\title{
Open Space - a Collaborative Process for Facilitating Tourism IT Partnerships
}

\author{
Philip Alford \\ Department of Tourism \& Leisure \\ University of Bedfordshire, UK \\ philip.alford@beds.ac.uk
}

\begin{abstract}
The success of IT projects depends on the success of the partnerships on which they are based However research has identified a significant rate of failure in these partnerships, predominantly due to an overly technical mindset, leading to the question: "how do we ensure that, as technological solutions are implemented within tourism, due consideration is given to human-centred issues?" The tourism partnership literature is explored for insights, revealing that issues connected with power, participation and normative positions play a major role. The method, Open Space, is investigated for its ability to engage stakeholders in free and open debate. This paper reports on a one-day Open Space event sponsored by two major intermediaries in the UK travel industry who wanted to consult their business partners. Both the running of the event and its results reveal how Open Space has the potential to address some of the weaknesses associated with tourism partnerships.
\end{abstract}

Keywords: tourism partnerships, Open Space, collaboration, stakeholder participation, boundary critique, normative position.

\section{Background}

Outside of the vertically integrated tour operations of big players such as TUI and First Choice, the tourism industry is not characterised by vertical and horizontal integration but rather by a network of partnerships which create the tourism product "assembly process" (Bramwell and Lane 2000: 1). According to Zhou (2004: 198): "Partnerships are important because of the nature of the hospitality and tourism industry, which is an interrelated group of businesses that serve the needs of travellers". The people focus is normally discussed in the business-to-consumer (B2C) domain in the context of the customer / supplier interaction as described above. However people also play the leading role in the business-to-business (B2B) domain, where the effective packaging and distribution of the tourism product requires collaboration and 'co-opetition' - "when organisations collaborate with players that they would normally regard as competitors" (Buhalis, 2003: 336). A study of the $\mathrm{B} 2 \mathrm{~B}$ processes for a cruise operator revealed that the accounting, sales, and inventory and fulfilment processes depended on partnerships within the supply chain (Alford, 2005). IT is an important facilitator of these partnerships but their success, first and foremost, is dependent not on technology but on the level of consensus among stakeholders. 


\section{Introduction}

This paper reports on applied research undertaken as part of the author's doctoral research (Alford, 2007b). A one-day event was organised in December 2002 to facilitate engagement with travel industry organisations by ntl travel and Galileo, two major intermediaries in the UK packaged leisure travel industry who wanted to investigate the issues and opportunities associated with travel distribution and technology. The workshop was facilitated by the author through the method, Open Space (Owen, 1997).

\subsection{Aim}

The overall aim of this paper is to investigate the role of Open Space (OS) as a method for engaging stakeholders during the IT consultation and planning stages.

\subsection{Objectives}

The objectives of this paper are to:

$>$ examine the role of partnerships in tourism IT and potential causes of failure

$>$ investigate the potential of OS in surfacing stakeholder normative positions

$>$ examine the potential for augmenting OS with boundary critique

\subsection{Purpose}

The purpose of this paper is to critique the contribution that OS can make to the stakeholder consultation process, and to strengthen OS through the incorporation of the theory and practice of boundary critique - a field of study located in Critical Systems Practice in Management Science. The author facilitated an OS event at the ENTER 2006 conference in Lausanne, Switzerland, in a workshop which explored collaboration between academics and industry in the Tourism IT field. In December 2007 the author will facilitate an executive forum, organised by Travel Technology Initiative (www.tti.org), to investigate the technology issues facing UK tour operators and agents.

\section{Theory/issues}

Despite their importance, there is a marked rate of partnership failure, particularly in inter-organisational, multiple stakeholder, business-to-business (B2B) IT implementation projects. The reasons lying behind this failure have been investigated in earlier studies by the author (Alford, 2004; 2007b; 2007a) and are encapsulated in the following problem definition in the author's $\mathrm{PhD}$ thesis: "multi stakeholder $\mathrm{B} 2 \mathrm{~B}$ Tourism IT projects are dominated by a view which privileges the technology at the expense of considering the interaction with that technology by human actors, and that this view is a contributory factor to a high rate of failure. We therefore have a problem which can be stated as: how do we ensure that, as technological solutions are implemented within tourism, due consideration is given to human-centred issues?" (Alford, 2007b:4). A range of methodological approaches were deployed in the author's doctoral research in addressing this question and this paper focuses on two of 
those methods, OS and boundary critique, both of which will be explained in more detail below.

In order to develop insights into the issues affecting tourism partnerships, this section now reviews the role of partnerships within tourism planning to enable a better understanding of the human issues which affect their success. Bramwell and Lane (2000: 3) pose some incisive questions relating to the inclusiveness of partnerships: "Are all participants in a partnership fully involved in the discussions, is there mutual respect and shared learning, and are all participants equally influential in the negotiations and decision-making"?. These are issues of empowerment and collaboration and the ability of OS to generate and sustain these is critiqued later in the paper.

Mason, Johnston et al's (2000c) case study of a project designed to bring stakeholders together to plan Arctic Tourism also allows for reflection on the questions posed by Bramwell and Lane as to the inclusiveness of the partnership process and the opportunity for participants to make equal contributions. It appears as if the terms of reference for the project were established by a core group of participants who attended early meetings and continued to have a dominant say. Restrictions, including funds for travel, computer access and language translation, meant that some participants could not make a contribution at all or at best on an ad-hoc basis. Although accepting the inevitability of such restrictions, the authors point out the "important implications for the process and the final product" (Mason, Johnston et al. 2000: 110). Clearly those participants who did not have the opportunity to contribute to the process, to express their views or to challenge those of others were going to have less ownership of the final product.

Commenting on the non-participation of the private sector in the Costa Dourada tourism project in Brazil, Medeiros de Araujo and Bramwell (2000: 292) caution that "if legitimate stakeholders are excluded or ignored then the quality and degree of acceptance of the project plans will be questionable". This has parallels with the English Tourism Network Automation project critiqued by Alford (2004), in which the national tourism office failed to secure the support of local authorities whose buyin was essential in determining the success of the project. Medeiros de Araujo and Bramwell (2000: 276) speculate that the exercise of power and coercion, "through access to material or financial resources, or through normative pressure" may have been a factor in the lack of private sector participation. For example, some sections of the private sector appeared to hold the normative position that it ought not to be involved in regional public sector projects.

Identifying both who is and who ought to be included in partnerships, and the normative positions which potential project partners hold, would therefore appear to be an important part of developing successful collaboration. Lawrence refers to "evaluative frameworks" (1997) which are made up of values and expectations which 
stakeholders apply to an issue in order to determine its legitimacy. Writing with reference to ecotourism in Canada, he refers to:

"the profit-oriented and conservation-oriented frameworks of the private entrepreneur and the environmental activist. Along with these, however, are the parochial economic and political ideologies of local government, the concerns of local citizens, and the cultural concerns of indigenous peoples" (1997: 310).

These evaluative frameworks are in effect normative frameworks which shape the way in which stakeholders think an issue ought to be addressed. Although Lawrence et al refer to one stakeholder changing another's perceptions and to "an approach that accommodates the multiple perspectives and evaluative frameworks of stakeholders", the paper does not elaborate on what this approach might be, other than to stipulate the need for "open communication and unhurried collaboration" (1997: 315).

The theory surrounding OS and boundary critique is now reviewed to develop a theoretical position from which partnerships might be developed and managed, and stakeholders' normative positions critiqued. OS is a process that encourages "emergence and self-organisation" (White 2002: 153). This runs throughout the event - from the co-creation of the agenda, merging discussion issues and organising the breakout spaces. One of the OS guiding principles - "Whatever happens is the only thing that could have" - "is a reminder that real learning and real progress will only take place when we all move beyond our original agendas and convention-bound expectations" (Owen 1997: 96). Bryson and Anderson (2000: 146) state that OS "is most useful when mission, vision, and goals are very unclear and very simple framing and analysis tools are needed" (. However Bryson and Anderson also point to the lack of theoretical support for OS and other large group interaction methods: "Another difficulty in researching LGIMs is that the theoretical bases for each approach need to be articulated better (Bryson \& Anderson, 2000: 152)." Lightfoot supports this assertion:

\footnotetext{
"Many organizations are now using OS, but little research has been conducted on its effectiveness. Anecdotal evidence from the previously cited organizations has shown that OS is extremely popular among participants and planners (Owen 1997), but there is no actual empirical evidence regarding which aspects of OS work well and if there is any lasting impact" (2003: 8).
}

With regard to "lasting impact", Bryson and Anderson claim that OS "is probably best for creating ideas, not necessarily action (2000: 152)."

Boundary Critique (BC) - a field of study within Critical Systems Practice potentially has the ability to strengthen the OS process. BC derives from earlier work by Ulrich $(1983 ; 1998 ; 2003)$. Ulrich's methodology, Critical Systems Heuristics, emerged from his work in attempting to establish a philosophical and epistemological basis for 
socially rational planning: "...in the context of applied social inquiry and planning, being critical therefore means to make transparent to oneself and to others the value assumptions underlying practical judgments, rather than concealing them behind a veil of objectivity" (Ulrich 1983: 20). He designed 12 critical boundary questions which cover four key areas of concern: motivation, control, expertise, and legitimacy, and which contrast the 'is' with the 'ought' encouraging critical reflection on the boundaries surrounding a system. For example, what is the purpose and what ought to be the purpose? What worldview underlines the system and what worldview ought to underline it?

Ulrich's methodology has been the catalyst for further BC studies. Midgley (1998; 2006), a proponent of boundary critique, focuses on the conflict that arises when groups make different boundary judgements on the same issue. He uses the concept of primary and secondary boundaries and the contested marginal area in between, as part of this focus. When one group makes a narrow boundary judgement (primary boundary) and another makes a wider judgement (secondary boundary), the contested area of difference between them lies in the marginal area. This area contains marginalised elements which effectively represent points of dispute between different stakeholders. The author used this approach in a recent presentation at the Travel Tourism Research Association (TTRA) European conference (Alford 2007a) in critiquing the EnglandNet case study where there was dispute between the national tourism office and an association of self catering businesses, essentially over what ought to be the role of a national tourism organisation (Travel Weekly 2004; Williamson 2004).

The following sections will now describe the OS methodology, report on an OS event, discuss the ability of OS to address some of the weaknesses associated with tourism partnerships, and evaluate the contribution with $\mathrm{BC}$ might make to strengthen the OS method.

\section{Methodology}

OS is based on a study of myth, ritual and culture in U.S.A. and Africa and aims to "combine the level of synergy and excitement present in a good coffee break with the substantive activity and results characteristic of a good meeting" (Owen 1997: 3). OS has been used extensively around the world by organisations, consultants and academics for the facilitation of group processes and meetings including change management, community projects, organisational (re) design, and strategy development (the OS community web site www.openspaceworld.org provides additional information and case studies).

The methodology incorporates the following steps: The headline issue: "An Open Space event usually takes the form of a theme or a question which the participants accept responsibility for tackling in collaboration with each other" (White 2002: 153). The theme for the ntl travel / Galileo event was "Travel Distribution \& Technology: the Issues and Opportunities". Opening the event: The participants are arranged in a 
large circle in the main meeting room with quarter flip chart paper, marker pens and masking tape in the centre. The circle is significant as it is a means by which equality is encouraged - there is no table or raised area for panellists at the front of the room. One wall of the room is kept completely free of any obstructions. The facilitator makes the introductions, states the theme and provides instructions for what will happen during the day. Then participants volunteer themselves to come into the centre, write down the issue that they want to debate, announce this to the rest of the group and then tape their issue to the wall (referred to by Owen as the "village market place"). They also post the time slot and location for their discussion on the board. By the time this process is finished the group has moved from a blank wall and a meeting with no agenda to a wall covered in issues and an agenda, time slots and breakout sessions, created by the participants themselves.

The village market place: The "market place" is now open for participants to sign up for the issue / debate in which they are interested. The person who initially suggested the issue is responsible for facilitating the discussion but the way in which this gets done is down to the group itself. The "law of two feet": As the discussion sessions convene, there is no rule that each session has to take the time allotted to it or that participants have to stay for the whole session. If they feel they have no more to contribute or to learn, they can move to another parallel session. However there should be a person (s) in the group responsible for submitting a written record / summary of the session. This summary should include a set of action points, designed to work towards proposed solutions to the issue. At the end of the session the summary is printed off and posted on to the "bulletin board" - blank walls around the venue, where participants can read it and add to it if they wish.

Concluding and prioritising issues: The participants reassemble in the main room in a circle and are given an opportunity to vote for those issues that they consider to be a priority. This can be achieved manually or electronically and is designed to facilitate action for the future.

\section{Results}

ntl travel and Galileo sponsored a one-day OS event in order to find out the distribution and technology issues which travel companies were facing. They were keen to get the 'whole system' in the room - tour operators, travel agents, IT intermediaries and IT suppliers - in order to get an overview of the global issues. Nixon (1998) identifies a long list of benefits, provided by large group methods such as OS and Future Search Conference, derived from getting the whole system into the room. These include "new organisational norms about how to behave are created" and "a sense of common vision and purpose is created" (Nixon, 1998: 6). In the preevent publicity, Galileo's Vice-President (EMEA) indirectly alludes to this "whole system" approach: "to brainstorm with people who would not normally get together to discuss these issues" (Fox, 2002). This makes it clear that the concept of creating an open communicative space is an unusual one in the travel industry. He was also conveying the point that the event was targeting a broad spectrum of people, not just 
technology experts, and that, for non-technology managers, discussing technologyrelated issues is not common practice within the travel industry. Therefore there was an opportunity to bring 'two worlds' together - the technical world and the business world which often do not mix well.

Galileo employed its marketing agency to assist with the wording of the invitation which captures the essence of OS:

A departure from the normal seminar format, this Open Space session is for industry 'doers' only. We want the people who, on a daily basis, tackle these issues head on. By creating a sales-free, non-competitive, experience-driven environment, we will be putting the core business needs front and centre. There is no agenda as such. We believe that by assembling the industry's most senior people, we can create our own agenda, an active agenda that will be relevant and real.

Representatives from 35 travel companies in the UK attended the event. The first surprise for delegates was the room layout with all chairs arranged in concentric circles. It was clear from the curious expressions on people's faces that this was unexpected and did not conform to the traditional theatre-style seating, which usually accompanies travel industry conferences. This had the effect of levelling the playing field and creating a shape conducive to participation and collaboration. When invited to nominate their issues, there was an almost immediate surge of activity with some delegates, in formal business suits, on their knees writing issues on the paper. Instantaneously, delegates were empowered to do something and to 'have a say' in creating the agenda. There is, inherently, an emancipatory element to this initial process, with delegates given the freedom to physically move around and propose ideas. In some cases delegates tackled this task individually and in other cases, collectively with someone else. This is in marked contrast to a traditional conference where delegates sit, theatre-style, waiting to hear from the 'experts'.

When all the issues were posted, the delegates gathered at the 'marketplace' to sign up for the discussions they were interested in joining. The output from the 10 discussion groups, posted on the walls around the main conference room, was voted on at the end of the event by delegates in order to prioritise the issues. The issue which attracted the most votes was entitled: "I know technology can be a great enabler - but how do I figure out what to do/invest in first?" This discussion was not primarily a technical one but rather focussed on how smaller travel agents in particular can choose the most appropriate technology for their business. The author, in the role of a delegate, joined this discussion group, which broadly divided into two groups - small agents or agency consortia and IT providers or IT Directors within an organisation. The output, as recorded by the group and by a travel journalist reporting on the event, reflects the concerns that smaller travel organisations have when looking for an IT partner for their business, and raises interesting questions concerning partnerships between smaller players and IT providers. It also highlights the different 
"evaluative frameworks" (Lawrence, Wickins et al. 1997: 310) of the two sub groups and the different perceptions of what a 'system' actually is.

From the agents' perspective, technology is often considered intimidating, resulting in inertia. It was revealed that travel agents felt at a disadvantage when negotiating with IT suppliers because of their relative lack of technical skills. One of the group's contributors, the owner of a small chain of independent agents, criticised technology suppliers for not allowing agents to trial technology systems before making a decision whether to purchase them or not. He often makes decisions based on the 'lesser of two evils' - hardly a rational approach. The primary need is for agents to get their brand in front of customers, and this business process is something that IT providers might not fully understand. Finally, the delivered IT solution often falls short of the agent's expectations. From the IT provider perspective, there is an onus on agents to become more "techno-aware", to articulate business requirements clearly, and to give IT providers enough time to understand their needs - these steps will help to prevent agents becoming a "victim". The use of words such as "intimidating" and "victim" also points to coercion and power as relevant issues.

Although not available as part of this empirical research, it is postulated that Ulrich's 12 critical boundary questions and Midgley's application of primary and secondary boundaries would be an effective means for not only stimulating debate but also for summarising stakeholders' normative positions. Ulrich's questions could be used to frame part of the discussion in a formal sense or simply as a tool to ask searching questions. For example, in the ntl / Galileo event, debating what is the purpose of an IT system and what ought to be its purpose would have explored further the differing positions held by small travel agents and by IT providers. The former highlighted the importance of putting their brand in front of the customer and the extent to which IT could enable that. Midgley's approach can be applied graphically to highlight points of difference between stakeholders - such a graphic approach was taken in the author's thesis (Alford 2007b) and his TTRA presentation (Alford 2007a). In the ntl / Galileo event this technique would have been useful in illustrating the business priorities of agents versus the technical priorities of providers. The suggestion is not that these two positions should be diametrically opposed but rather to highlight the potential points of difference between the means-ends efficiency which often dominates technical perspectives and the more 'messy' reality of business and organisational issues.

Recommendations reached by the group included "Talk to other companies in a similar position", "Educate yourself on technology", and "Understand benefits/costs/timeframes - be realistic". A suggestion was made that case studies of best practice IT use in the travel agency community be developed and published, thereby providing a useful resource and a means of addressing the power imbalance through knowledge transfer. This technique was identified by Medeiros de Araujo and Bramwell (2000) for involving stakeholders in a project. Such case studies would contain insights which could then further inform the discussion and partnership 
process. Where, for example, technology suppliers lay claim to certain benefits accruing from a system, travel agents must be empowered to debate that claim from a position of equal strength. The use of case studies of best practice among travel agents would enable this by contributing evidence to assist in the debate of those claims. For example, one of the primary objectives of travel agents which arose from the OS discussion is "to put their brand in front of their customers" - an example of IT as an enabler of business processes; the ability of technology to enable this could be ascertained through detailed case study analysis and discussion. In this way the distortion is eased, as travel agents are in less of a position of powerlessness and now possess some knowledge, from a trusted source, which they can use in their deliberations and negotiations. It empowers them to raise issues with their technology suppliers from a position of strength.

The question remains as to the next step, after an OS event has finished, normative issues have been surfaced and a spirit of collaboration attained. One delegate, after the ntl / Galileo event, praised the participant-centred nature of OS, but questioned its ability to facilitate real action-oriented change. This limitation was identified earlier by Bryson and Anderson in their evaluation of a range of large-group interaction methods (LGIMs). The ntl / Galileo event did allow time for voting on the issues in a plenary session, but of course this is no guarantee that anything will be done afterwards. Although the groups reached conclusions and made recommendations, tangible follow up was never part of the original objective which the two sponsoring organisations set for the event. This was principally to create "whole system" insights, increase awareness and generate positive publicity, all of which were undoubtedly achieved by the OS event. Furthermore, any follow up action would have taken place over the longer term, when the author's relationship with the companies had finished. Again, while not part of the original research agenda for this event, it is postulated that the methods linked to $\mathrm{BC}$ could provide useful frameworks for facilitating future action. For example, by clearly identifying stakeholders' normative positions and points of difference between boundaries, a plan of action for further exploring and addressing these issues could be recommended.

\section{Conclusions and future research}

The original problem was stated as: "how do we ensure that, as technological solutions are implemented within tourism, due consideration is given to humancentred issues? (Alford 2007b:4)" The issues arising from the tourism partnership literature related to the importance of empowering partners, providing them with the opportunities to contribute equally and free from coercion, and identifying their evaluative, normative frameworks. There are a number of elements to Open Space which address these issues and point to its role as a suitable method to facilitate more effective Tourism IT partnerships. The review of tourism partnerships revealed that the involved and affected concept of inclusivity is a central one in ensuring the success of partnerships. OS gives all delegates the opportunity to effectively construct their own agenda for the day, thereby enabling those affected by an issue to have their voice heard, regardless of status. There is one caveat here in terms of the 
ntl / Galileo event - namely that it was invitation-only, with a potential list of invitees drawn up by the two sponsoring companies. This presented challenges to the author as a researcher and required active intervention in order to ensure that small independent travel agents were adequately represented at the seminar. This intervention added an important perspective to the discussions reported in this paper.

In planning discussions with TTI about its forthcoming Executive Forum, which will be facilitated by OS, a number of suggestions were discussed for generating follow up action; monitoring the effectiveness of these suggestions will form the basis for a future research agenda. Firstly, delegates should be asked to attach their names to issues which they would be prepared to take responsibility for following up. A second suggestion, drawing on a shortcoming of the ntl / Galileo event, is to allow more time in the plenary to facilitate discussion of prioritised issues in addition to voting - thereby combining qualitative with quantitative insights. A third possibility is to allow for sessions after the prioritisation - 'action-planning' sessions, which would specifically be devoted to what action needed to be taken and by whom. The author will also take the opportunity to investigate the contribution which $\mathrm{BC}$ methods can make to strengthening the OS process. 


\section{References}

Alford, P. (2004). Critical theory - an alternative solution to IT planning implementation problems in tourism. In Information and Communications Technologies in Tourism, A. Frew (ed). Wien/New York, Springer: 271-282.

Alford, P. (2005). A framework for mapping and evaluating business process costs in the tourism industry supply chain. In Information and Communications Technologies in Tourism, A. Frew (ed). Wien/New York, Springer: 125-136.

Alford, P. (2007a). A case analysis of the failure of business to business multi stakeholder Tourism IT. Unpublished presentation made at the Travel \& Tourism Research Association (Europe) conference 'Tourism, Mobility \& Technology', Nice, France

Alford, P. (2007b). A communicative model for stakeholder consultation: towards a framework for action inquiry in tourism IT, University of Bedfordshire: 318 pages.

Bramwell, B. and B. Lane (2000). Collaboration and partnerships in tourism planning. In Tourism collaboration and partnerships: politics, practice and sustainability, $\mathrm{B}$. Bramwell and B. Lane (ed). Clevedon, UK, Channel View Publications: 1-19.

Bryson, J. and S. Anderson (2000). Applying large-group interaction methods in the planning and implementation of major change efforts. Public Administration Review, 60 (2): 143162.

Buhalis, D. (2003). eTourism: Information technology for strategic tourism management. London, FT Prentice Hall.

Fox, L. (2002). Open House. Travel Trade Gazette, 18th November: 43.

Lawrence, T., D. Wickins, et al. (1997). Managing legitimacy in ecotourism. Tourism Management, 18 (5): 307-316.

Lightfoot, E., V. Pappas, et al. (2003). Using open space technology to enable citizens to set the agenda for state disability planning. Journal of Disability Policy Studies, 14 (1): 7-16.

Mason, P., M. Johnston, et al. (2000). The World Wide Fund for Nature Arctic tourism project. In Tourism collaboration and partherships - politics, practice and sustainability, B. Bramwell and B. Lane (ed). Clevedon, UK, Channel View Publications: 98-116.

Medeiros de Araujo, L. and B. Bramwell (2000). Stakeholder assessment and collaborative tourism planning: the case of Brazil's Costa Dourada project. In Tourism collaboration and partnerships - politics, practice and sustainability, B. Bramwell and B. Lane (ed). Clevedon, UK, Channel View Publications: 248-271.

Midgley, G. (2006). Systemic intervention for public health. American Journal of Public Health, 96 (3): 466-472.

Midgley, G., I. Munlo, et al. (1998). The theory and practice of boundary critique: developing housing services for older people. Journal of the Operational Research Society, 49: 467-478.

Nixon, B. (1998). Creating the futures we desire - getting the whole system into the room: part I. Industrial and Commercial Training, 30 (1): 4-11.

Owen, H. (1997). Open space technology: A user's guide. San Francisco, Berrett-Koehler.

Travel Weekly (2004). U-turn over Englandnet. Travel Weekly, 68.

Ulrich, W. (1983). Critical heuristics of social planning: A new approach to practical philosophy. Berne, Haupt.

Ulrich, W. (1998). If systems thinking is the answer, what is the question? Lincoln: Lincoln School of Management. 1-19 pp.

Ulrich, W. (2003). Beyond methodology choice: critical systems thinking as critically systemic discourse. Journal of the Operational Research Society, 54 (4): 325-342.

White, L. (2002). Size matters: large group methods and the process of operational research. Journal of the Operational Research Society, 53 (2): 149-160.

Williamson, E. (2004). Web of intrigue over EnglandNet. Travel Weekly, 4.

Zhou, Z. (2004). E-commerce and information technology in hospitality and tourism. New York, Thomson. 